\title{
Studies on Warpage about Printed Wiring Board*
}

\author{
Shin-ichi KoyAnAgi**
}

\section{Introduction}

In the previous reports, we explained foundmental data about reliabilities of the printed wiring board. In this paper, we report the experimental results about warpage of the board which sometimes causes troubles for the electronic equipments involving the printed circuit system.

Today, printed circuit method is widly used in various electrical apparatus, but among them when it is adapted as Plug-in System shown in Photo 1, warpage of the board often rises the contact failure between boards and connectors of the apparatus.

On the mechanism as the warpage, simple explanations are as following.

a) Under high temperature of the dip-soldering process, the base material of the board shrinks by the reaction of condensation.

b) Under various humidities, elongation and shrinkage of the board occur due to absorption and desorption of moisture.

c) There is difference of expansion coefficient between base material and copper foil of the board.

These factors cause the inner stress between base material and

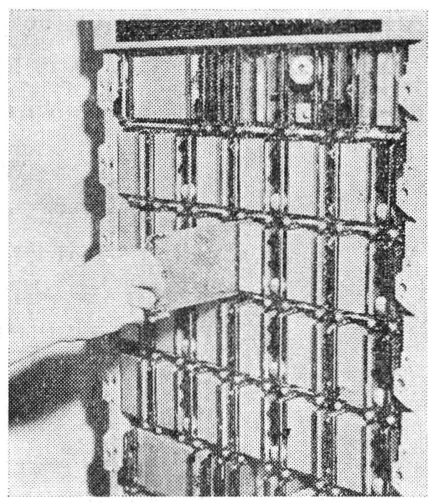

Photo. 1 Printed wiring boards using plug-in system. adhesive copper foil, and then, this stress rises the strain to the warpage.

\section{Experimental Results}

a) Warpage due to moisture.

After maintaining the specimens into the chambers of various humidities for long time, we measured the relation between warpage and water absorption of the board, where as the specimens we used phenolic base materials. The direction of warpage depends on humidity surrounding the board, and the change of direction seems to occur at about 50\% R.H. These results are shown in Fig. 1 and 2.

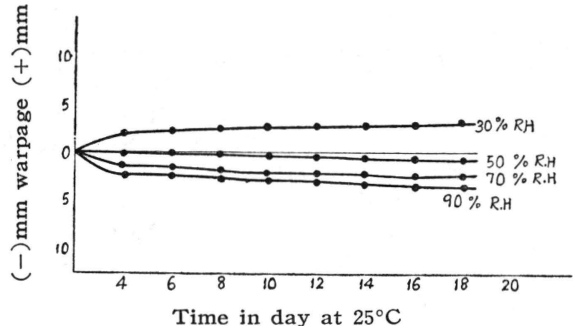

Fig. 1 Warpage v.s. humidities of boards (phenol base)

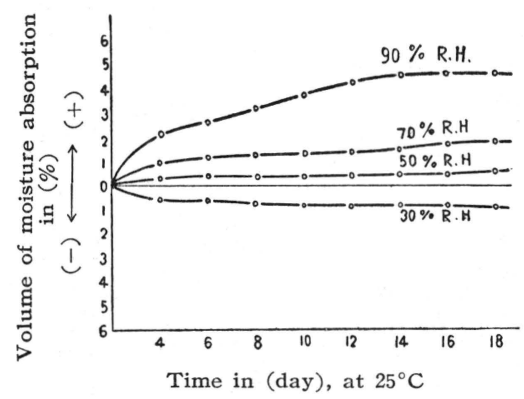

Fig. 2 Moisture absorption v.s. humidities of boards.

b) Warpage after dip-soldering process.

The warpage after dip-soldering process can be represented by the following experimental formula,

* Studies on Printed Circuits (Part 4)

** Tamagawa Plant, Nippon Electric Co., Ltd. Kawasaki.

The original written in Japanese can be seen in J. Electrochem. Soc. Japan 28, 193 (1960). 


$$
y=\frac{ \pm\left\{\left(A_{2}+S\right)-A_{1}\right\} T s \times 6 m n \times l^{2}}{h(1+m)(1+n)(1+m n)}
$$

where $\quad y:$ quantity of warpage of the board,

$A_{1}, A_{2}$ : thermal expansion coeff. of base material and copper foil, respectievly,

$S$ : shrinkage by heating of base material,

Ts : softening point of base materials,

$m: m=h_{2} / h_{1}$ ( $h_{1}$ and $h_{2}$ are thickness of copper foil and base material, respectively.)

$n: n=E_{2} / E_{1}$ ( $E_{1}$ and $E_{2}$ are Young's Modulus of copper and base material, respectively.) $l$ : length of the specimen.

After measuring factors of the experimental formula, $A_{1}, A_{2}, S, m$ and $n$ etc., about boards consisted of various synthetic resin, we had comparatively good agreement between calculated and measured values. These results are shown in Table 1 .

Table 1 Warpage of Various Base Matenals of the Boards

\begin{tabular}{|c|c|c|c|c|c|c|}
\hline \multirow{2}{*}{ No. } & \multirow{2}{*}{ Material } & \multirow{2}{*}{$A_{2}\left(10^{-7} /{ }^{\circ} \mathrm{C}\right) 25^{\circ} \mathrm{C} \sim T_{s}$} & \multirow{2}{*}{$\begin{array}{l}S\left(10^{-7} /^{\circ} \mathrm{C}\right) \\
25^{\circ} \mathrm{C} \sim T_{s}\end{array}$} & \multirow{2}{*}{$\begin{array}{c}E_{2} \\
\left(\mathrm{~kg} / \mathrm{mm}^{2}\right)\end{array}$} & \multirow{2}{*}{$\begin{array}{l}y(\mathrm{~mm}) \\
\text { Calc. }\end{array}$} & \multirow{2}{*}{$\begin{array}{r}\text { Warpage } \\
\text { Meas. }\end{array}$} \\
\hline & & & & & & \\
\hline 1 & Phenol Base (Hot Punch) & $197 T_{s}=130$ & 51.8 & 118 & +1.5 & +1.1 \\
\hline 2 & Phenol Base (Cold Punch) & $144 \quad T_{s}=125$ & 37.0 & 982 & +0.4 & +0.4 \\
\hline 3 & Phenol Base (XXX-P) & $120 \quad T_{s}=130$ & 51.0 & 733 & +0.1 & +0.2 \\
\hline 4 & Melamin $\sim$ Glass & $116 \quad T_{s}=115$ & 28.2 & 2660 & -0.3 & -0.5 \\
\hline 5 & Polyester Glass & $83.0 T_{s}=150$ & 26.2 & 1660 & -1.3 & -1.1 \\
\hline 6 & Epoxy $\sim$ Glass & $118 T_{s}=150$ & 10.5 & 1185 & -0.6 & -0.4 \\
\hline 7 & Silic on $\sim$ Glass & $76.625 \sim 230$ & 5.0 & 2020 & -2.8 & -2.0 \\
\hline 8 & Teflon $\sim$ Glass & $42.425 \sim 230$ & 45.2 & 1255 & -2.7 & -1.9 \\
\hline
\end{tabular}

(Received October 15, 1958) 